\title{
Usefulness of the Triglycerides to High-Density Lipoprotein Cholesterol ratio (TG/HDL-C) in prediction of metabolic syndrome in Polish obese children and adolescents
}

\author{
Monika Krawczyk, Małgorzata Rumińska ${ }^{凶}$, Ewelina Witkowska-Sędek, Anna Majcher and \\ Beata Pyrżak
}

Department of Pediatrics and Endocrinology, Medical University of Warsaw, Warsaw, Poland

\begin{abstract}
The triglycerides to high-density lipoprotein cholesterol ratio (TG/HDL-C) is a useful surrogate marker of insulin resistance and cardiovascular risk factors. We aimed to assess the relationship between the TG/HDL-C ratio and insulin resistance (IR) and its usefulness in prediction of the metabolic syndrome (MS). This retrospective study involved 122 obese children with the mean age of $11.6 \pm 3$ years and their 58 healthy lean peers. Anthropometric measurements, blood pressure, the plasma lipid profile and oral glucose tolerance test (OGTT) were analyzed. Based on the obtained results, the TG/HDL-C ratio and surrogate insulin resistance indices (HOMA-IR, FGIR, QUICKI, OGIS, Matsuda index) were calculated. The TG/HDL-C ratio positively correlated with weight, waist circumference, waist to hip ratio (WHR), lipid profile, HOMA-IR, fasting insulin and insulin measurements during OGTT, and negatively correlated with FGIR, QUICKI, OGIS, and the Matsuda index. Obese children with the TG/HDL-C ratio $\geq 3$ (47.5\%) had higher values of WHR and HOMA-IR, and lower ones of FGIR, QUICKI, OGIS, and the Matsuda index when compared to their obese peers with the TG/HDL-C $<3$. The area under the curve (AUC) calculated for each insulin resistance index in prediction of the metabolic syndrome was the largest for the TG/HDL$C$ ratio $(0.8936,95 \% \mathrm{Cl}: 0.809-0.977, p=0.000)$. For 1 unit increase in the TG/HDL-C ratio, the odds for having MS increased by 2.09 times. The TG/HDL-C ratio is a good surrogate marker of insulin resistance in obese children. When comparing the usefulness of some IR markers in prediction of the metabolic syndrome, the TG/HDL-C ratio seems to be the best one and should be used in clinical practice to identify children at risk of metabolic syndrome development.
\end{abstract}

Key words: TG/HGL-C ratio, insulin resistance, metabolic syndrome, obesity, children

Received: 23 July, 2018; revised: 19 September, 2018; accepted: 18 October, 2018; available on-line: 19 November, 2018

e-mail: mruminska@wum.edu.pl

Abbreviations: AUC, area under the curve; BMI, body mass index $\mathrm{BP}$, blood pressure; $\mathrm{Cl}$, confidence interval; $\mathrm{DBP}$, diastolic blood pressure; \%FAT, body fat percentage; FGIR, fasting glucose to insulin ratio; HDL-C, high-density lipoprotein cholesterol; HOMA-IR, homeostasis model assessment for insulin resistance index; IDF, International Diabetes Federation; IOTF, International Obesity Task Force; IR, insulin resistance; LDL-C, Low-density lipoprotein cholesterol; LMS, Least mean squares; MS, metabolic syndrome; NHANES, National Health and Nutrition Examination Survey; OGTT, oral glucose tolerance test; QUICKI, Quantitative insulin sensitivity check index; OGIS, Oral Glucose Insulin Sensitivity Index; OR, odds ratios; ROC, Receiver operating characteristic; SBP, systolic blood pressure; S.D., standard deviation; SDS BMl, standard deviation score Body Mass Index; TC, total cholesterol; TG, triglycerides; WBISI, whole body insulin sensitivity index; WC, waist circumference; WHtR, waist to height ratio; WHR, waist to hip ratio; WHO, World Health Organization

\section{INTRODUCTION}

Childhood obesity is an important public health problem worldwide. There are numerous complications associated with excessive fat mass that lead to the deterioration of the health of the whole population. It is wellknown that with the increase in the body mass index (BMI) value, the risk of death also increases (Berrington de Gonzalez et al., 2010).

The fundamental disorder related to obesity is insulin resistance (IR), which drives a string of metabolic processes leading to development of proatherogenic lipid profile, type 2 diabetes mellitus and high blood pressure (Nadeau et al., 2011). It has been also well-known that insulin resistance, together with other components of the metabolic syndrome, contributes to the development of atherosclerosis.

The gold standard method to measure IR is by use of the hyperinsulinemic euglycemic clamp, rarely performed in children because of its invasiveness, complexity, timeconsumption and high costs. In clinical trials indirect methods are often used which are calculated on the basis of timely assessment of fasting glucose and insulin concentration (e.g. FGIR - fasting glucose to insulin ratio, HOMA-IR - homeostasis model assessment for insulin resistance index, QUICKI - Quantitative insulin sensitivity check index ) and during the oral test of glucose load (e.g. OGIS - Oral Glucose Insulin Sensitivity Index, Matsuda index) (Ten et al., 2004; Levy-Marchal et al., 2010). In practice, HOMA-IR is generally used in adults and also approved for children and adolescents. These tests are not standardized in children and are usually performed in hospital settings (Chandrasekhar et al., 2014).

Surprisingly, previous studies have shown that the triglycerides (TG) to high-density lipoprotein cholesterol (HDL-C) concentration ratio correlates well with insulin resistance and may be an alternative tool for evaluation of an increased risk of IR development (Giannini et al., 2011). Moreover, the TG/HDL-C ratio reflects atherosclerotic lipid changes better than each of the lipoproteinograms interpreted separately, and may be effective in screening for the metabolic syndrome (Olson et al., 2012; Liang et al., 2015). Due to the fact that measurements of TG and HDL-C concentrations are routine and cost-effective outpatient tests, they would greatly facilitate the assessment of reduced insulin sensitivity. Some studies, however, suggest that the relationships described above do not apply 
to all children and all ethnic groups (Giannini et al., 2011; Sumner et al., 2005; Bridges et al., 2016). There is a need for well-planned studies to confirm the usefulness of the TG/HDL-C ratio in identification of children with a high risk of development of insulin resistance and other obesity-related cardiometabolic disturbances.

The aim of this study was to determine the relationship between the TG/HDL-C ratio and surrogate insulin resistance indices and other components of the metabolic syndrome, and to compare it to other indirect IR measurements to establish its usefulness in prediction of MS in Polish obese children and adolescents.

\section{MATERIAL AND METHODS}

Study population. A retrospective study was performed on 122 children with simple obesity, 52 girls and 70 boys, whose chronological age ranged between 5.3 and 17.9 years (mean age $11.6 \pm 3$ years). The control group included 58 children (23 girls, 35 boys) of the same age (mean age $11.7 \pm 3$ years) with normal somatic parameters. Patients originated from the Department of Paediatrics and Endocrinology at the Medical University of Warsaw. Children with endocrine and genetic obesity, diabetes and hypertension, and those receiving therapy that could affect the lipid and carbohydrate metabolism were excluded from the study. Based on medical documentation data from physical examination, auxological and biochemical parameters were taken into consideration. The project received approval of the Ethical Committee at the Medical University of Warsaw.

In order to evaluate obesity, criteria developed by the International Obesity Task Force (IOTF) were used (Cole et al., 2000). The BMI standard deviation score (SDS BMI) expressing the degree of obesity was calculated by means of the LMS method (Cole, 1990). In this study, paediatric metabolic syndrome (MS) was diagnosed according to the 2007 International Diabetes Federation (IDF) consensus for children older than 10 years. The presence of abdominal obesity (WC, waist circumference $\geq 94 \mathrm{~cm}$ in boys and $\geq 80 \mathrm{~cm}$ in girls) and two or more of the following components: elevated values of $\mathrm{TG} \geq 150 \mathrm{mg} / \mathrm{dl}$, lower levels of HDL-C $<40 \mathrm{mg} / \mathrm{dl}$, increased blood pressure (SBP $\geq 130$ $\mathrm{mmHg}$ and/or $\mathrm{DBP} \geq 85 \mathrm{mmHg}$ ), abnormal fasting plasma glucose values $(\geq 100 \mathrm{mg} / \mathrm{dl})$, allow the recognition of MS (Zimmet et al., 2007).

Anthropometric measurements. In each patient body height $(\mathrm{cm})$, body weight $(\mathrm{kg})$, waist and hip circumference $(\mathrm{cm})$ and thickness of three skinfolds ( $\mathrm{mm})$ using the Harpenden Skinfold Caliper were analyzed. Based on the above measurements, the Body Mass Index (BMI), waist to hip ratio (WHR), waist to height ratio (WHtR) and body fat percentage (\%FAT) were calculated. The anthropometric measurements were taken by trained personnel and health examinations were performed by paediatricians.

Blood pressure. Three blood pressure (BP) measurements were used for analysis and the mean value was calculated. Polish reference chart of systolic and diastolic $\mathrm{BP}$ depending on gender, age and height was used to evaluated BP in each patient (Ostrowska-Nawarycz et al., 2008). Appropriate BP values were defined as mean systolic (SBP) and/or diastolic blood pressure (DBP) values below the 90th percentile. Hypertension was diagnosed when SBP and/or DBP values were above the 95th percentile. Mean blood pressure values between the 90th and 95th percentiles were defined as border values.

Biochemical analysis. Serum concentrations of total cholesterol (TC, $\mathrm{mg} / \mathrm{dl}$ ), high-density lipoprotein cho- lesterol (HDL-C, mg/dl) and triglycerides (TG, mg/ dl) were measured after a 12 -hour fast by colorimetric enzymatic method using a Vitros 5600 analyzer (Ortho Clinical Diagnostics). Low-density lipoprotein cholesterol concentration (LDL-C, $\mathrm{mg} / \mathrm{dl}$ ) was calculated based on the Friedewald formula (LDL-C $=$ TC-TG/5-HDL-C). Results of the lipid profile were interpreted according to the American Heart Association (Hayman et al., 2007). The TG/HDL-C ratio at a value $\geq 3$ was considered to be closely correlated with IR (McLaughlin et al., 2003).

Obese subjects also underwent an oral glucose tolerance test (OGTT with $1.75 \mathrm{~g}$ glucose solution per $1 \mathrm{~kg}$ body weight, maximum $75 \mathrm{~g}$ of glucose). Glucose concentrations were determined in blood serum by glucose oxidase colorimetric method using a Vitros 5600 analyzer. Serum concentrations of insulin were measured by an immunoassay using an IMMULITE 2000 Xpi Analyzer (Siemens). Hyperinsulinism has been identified as fasting insulin level $\geq 15 \mu \mathrm{IU} / \mathrm{ml}$, and/or maximum level of $\mathrm{OGTT} \geq 150 \mu \mathrm{IU} / \mathrm{ml}$, and/or insulin level at 120 minutes during OGTT $\geq 75 \mu \mathrm{IU} / \mathrm{ml}$ (Ten et al., 2004). Homeostasis model assessment for insulin resistance index (HOMA-IR), fasting glucose to insulin ratio (FGIR), quantitative insulin sensitivity check index (QUICKI), oral glucose insulin sensitivity index (OGIS) and the Matsuda index were calculated to determine the status of insulin resistance (Ten et al., 2004). HOMA-IR $\geq 3.16$ shows evidence of insulin resistance (Keskin et al., 2005).

Statistical analysis. Data obtained from patients in the study and control groups are expressed as mean with standard deviation (S.D.) or median with minimum and maximum values. The anthropometric and biochemical measurements in both groups were compared by using the T-test for parameters in a normal distribution, and in case of nonnormal distribution by the Mann-Whitney test. Correlations between the variables were assessed using the Spearman coefficient. Receiver operating characteristic (ROC) curve was drawn and the area under the curve (AUC) was calculated for the TG/HDL-C ratio and other surrogate insulin resistance (IR) indices in order to discriminate which of the mentioned above parameters is more useful in prediction of the metabolic syndrome (MS). Using logistic regression analysis, the odds for MS were calculated. Values are presented as odds ratios (OR) with 95\% confidence interval $(\mathrm{Cl})$. The data analyses were carried out using the statistical package SPPS 19 software. A $p$ value $<0.05$ was considered as the indicator of statistical significance.

\section{RESULTS}

Anthropometric and clinical data describing and comparing the obese and control group children are presented in Table 1.

In the obese group children, $26(21.3 \%)$ had an elevated concentration of total cholesterol (TC>200 mg/dl). Incorrect concentration of high-density lipoprotein cholesterol (HDL-C $<40 \mathrm{mg} / \mathrm{dl}$ ) was detected in $43(35.2 \%)$ obese patients. High concentration of LDL cholesterol (LDL-C $\geq 130 \mathrm{mg} / \mathrm{dl}$ ) was found in $18(14.8 \%)$ children and high amount of triglycerides ( $T G \geq 110 \mathrm{mg} / \mathrm{dl}$ ) was found in $76(62.3 \%)$ individuals in the same group.

Abnormal glucose tolerance was diagnosed in 26 $(21.3 \%)$ obese children. Increased fasting insulin $(\geq 15$ $\mu \mathrm{IU} / \mathrm{ml})$ was found in $55(45 \%)$ of the obese children. In the oral glucose tolerance test (OGTT), increased values of insulin $(\geq 150 \mu \mathrm{IU} / \mathrm{ml})$ were found at $30 \mathrm{~min}-$ utes in $19(15.5 \%)$ patients, at 60 minutes in $21(17.2 \%)$ patients, at 90 minutes in $18(14.7 \%)$ patients. Insulin 
Table 1. Comparison of anthropometric and biochemical parameters between the obese and control children groups

\begin{tabular}{|c|c|c|}
\hline Variable & Control group $(n=58)$ & Obese group $(n=122)$ \\
\hline Age (years) & $11.7 \pm 3.0$ & $11.6 \pm 3.01$ \\
\hline Height $(\mathrm{cm})$ & $159.0(128.1-186.5)$ & $156.0(110.0-187.1)$ \\
\hline Body weight $(\mathrm{kg})$ & $46.77 \pm 12.9$ & $72.34 \pm 24.11^{* * *}$ \\
\hline BMI $(\mathrm{kg} / \mathrm{m} 2)$ & $18.7(12.7-23.1)$ & $28.8(20.7-43.8)^{* * *}$ \\
\hline SDS BMI & $0.1(-2.2-1,4)$ & $2.7(2.0-4.8)^{* * *}$ \\
\hline$W C(\mathrm{~cm})$ & $64.32 \pm 6.62$ & $90.27 \pm 12.27^{* * *}$ \\
\hline $\mathrm{HC}(\mathrm{cm})$ & $84.5(61.0-97.0)$ & $102.0(72.0-131.0)^{* * *}$ \\
\hline WHR & $0.79(0.64-0.87)$ & $0.9(0.71-1.04)^{* * *}$ \\
\hline WHtR & $0.4 \pm 0.02$ & $0.58 \pm 0.05^{* * *}$ \\
\hline$\%$ FAT & $19.8(9.6-31.8)$ & $33.5(20.2-53.1)^{* * *}$ \\
\hline fasting glucose (mg/dl) & $80.5(68.0-114.0)$ & $82.0(59.0-106.0)$ \\
\hline $\mathrm{TC}(\mathrm{mg} / \mathrm{dl})$ & $157.5 \pm 22.4$ & $176.9 \pm 30.03^{* * *}$ \\
\hline $\mathrm{HDL}-\mathrm{C}(\mathrm{mg} / \mathrm{dl})$ & $54.0(33.0-92.0)$ & $42.0(25.0-92.0)^{* * *}$ \\
\hline $\mathrm{LDL}-\mathrm{C}(\mathrm{mg} / \mathrm{dl})$ & $85.1 \pm 24.2$ & $105.8 \pm 27.2^{* * *}$ \\
\hline $\mathrm{TG}(\mathrm{mg} / \mathrm{dl})$ & $74.0(23.0-167.0)$ & $123.0(39.0-458.0)^{* * *}$ \\
\hline $\mathrm{TG} / \mathrm{HDL}-\mathrm{C}$ & $1.3(0.9-4.3)$ & $2.9(0.5-14.3) * * *$ \\
\hline
\end{tabular}

Data are presented as mean \pm standard deviation (S.D.) or median with minimum and maximum values, as appropriate. BMI, Body Mass Index; WC, Waist circumference; HC, Hip circumference, WHR-Waist to hip ratio; WHtR, Waist to height ratio; \% FAT, \% of body mass; TC, Total cholesterol; TG, Triglycerides; HDL-C, High-density lipoprotein cholesterol; LDL-C, Low-density lipoprotein cholesterol; TG/HDL-C, Triglycerides to high-density lipoprotein cholesterol ratio. ${ }^{* * *} p<0.001,{ }^{* *} p<0.01,{ }^{*} p<0.05$

level exceeding $75 \mu \mathrm{IU} / \mathrm{ml}$ at 120 minutes was detected among $55(45 \%)$ patients. The median HOMA-IR value was 2.89. Insulin resistance (HOMA-IR $\geq 3.16$ ) was diagnosed among $43.2 \%$ of obese children. The median FGIR, QUICKI, OGIS and Matsuda index values were 5.8; 0.14; 425.65; and 3.29, respectively.

Systolic blood pressure (SBP) above the 95th percentile was detected among $6.1 \%$ of the obese children; diastolic blood pressure (DBP) above the 95th percentile was among $14.2 \%$ of patients.

The International Diabetes Federation (IDF) criteria for metabolic syndrome (MS) were analysed in 84 obese children older than 10 years. The diagnosis of MS was made in 17 children, which accounted for $20.2 \%$ of the group. Characteristics of anthropometric and biochemical parameters, blood pressure in obese children with or without the metabolic syndrome IDF criteria are presented in Table 2.

The median value of the TG to HDL-C concentration ratio in obese children and adolescents was higher than in their healthy peers $(2.9$ vs. $1.3, p=0.000)$. The TG/HDL-C ratio $\geq 3$ was found in 58 obese children $(47.5 \%)$ and they had higher values of WHR, HOMAIR, and lower of FGIR, QUICKI, OGIS, and the Matsuda index when compared to their obese peers with the TG/HDL-C $<3$ (Table 3). In children with the metabolic syndrome (MS), the median TG/HDL-C value was 5.33, in comparison to obese children who did not meet the criteria of MS; their TG/HDL-C was $2.74 \quad(p=0.000)$ (Fig. 1). There were no significant differences in HOMA-IR, QUICKI, and the OGIS values between these groups. Only the FGIR and Matsuda index were significantly different ( $p=0.044 ; 0.036$, respectively) (Table 2).

Among the obese children, the TG/HDL-C ratio was positively correlated with weight $(\mathrm{r}=0.202, \mathrm{p}=0.028), \mathrm{WC}$ $(\mathrm{r}=0.236, p=0.01)$, WHR $(\mathrm{r}=0.192, p=0.037), \mathrm{TC}(\mathrm{r}=0.221$, $p=0.016)$, TG ( $\mathrm{r}=0.936, p=0.000)$, and HDL-C $(\mathrm{r}=-0.760$, $p=0.000)$. No statistically significant correlations were found between the TG/HDL-C ratio and fasting or OGTT glucose levels. However, the TG/HDL-C ratio was correlated with fasting insulin $(\mathrm{r}=0.266, p=0.004)$, and insulin measurements during OGTT: at 30 minutes $(\mathrm{r}=0.192$, $p=0.039)$, at 60 minutes $(\mathrm{r}=0.192, p=0.04)$, at 90 minutes $(\mathrm{r}=0.178, p=0.05)$, at 120 minutes $(\mathrm{r}=0.196, p=0.035)$ and also with HOMA-IR ( $\mathrm{r}=0.261, p=0.004)$, FGIR ( $\mathrm{r}=-0.254$, $p=0.006)$, QUICKI ( $\mathrm{r}=-0.262, p=0.004)$, OGIS ( $\mathrm{r}=-0.204$, $p=0.028)$ and the Matsuda index $(\mathrm{r}=-0.34, p=0.002)$. A statistically significant positive correlation was found with SBP $(\mathrm{r}=0.198, p=0.05)$, but not with DBP.

Figure 2 shows the ROC curve analysis for each insulin resistance indicator as a predictor of the metabolic

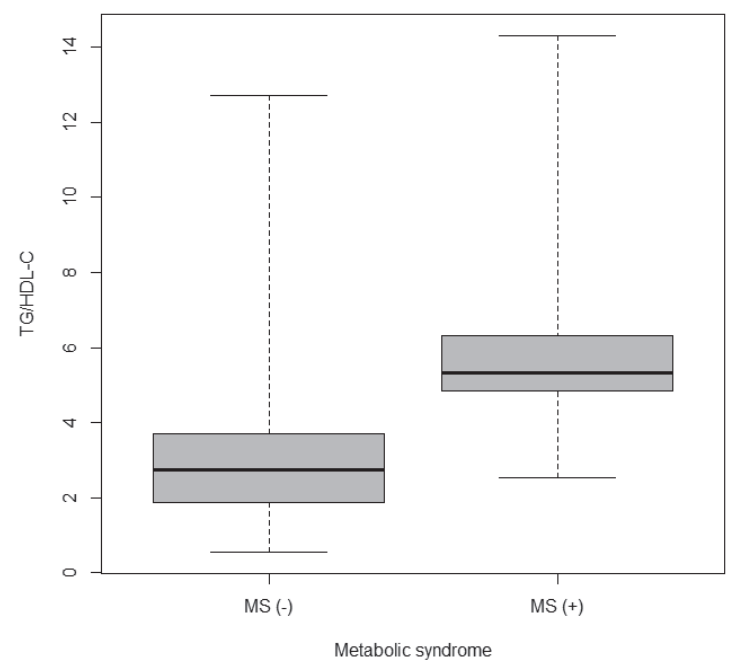

Figure 1. Comparison of median TG/HDL-C values in obese children with metabolic syndrome and their peers, who did not meet the criteria of the metabolic syndrome. 
Table 2. Comparison of anthropometric and biochemical parameters, surrogate insulin resistance measurements, and blood pressure in the obese children $>10$ years old with and without metabolic syndrome criteria.

\begin{tabular}{|c|c|c|c|}
\hline Variable & Total $(n=84)$ & MS (-) $(n=67)$ & MS (+) $(n=17)$ \\
\hline Age (years) & $13.0(10.1-17.9)$ & $13.0(10.1-17.7)$ & $13.5(12.0-17.9)^{*}$ \\
\hline Height (cm) & $162.3 \pm 11.09$ & $160.8 \pm 10.94$ & $168.4 \pm 9.75^{*}$ \\
\hline Body weight $(\mathrm{kg})$ & $83.6 \pm 19.84$ & $81.4 \pm 20.5$ & $92.2 \pm 14.52^{*}$ \\
\hline BMI (kg/m2) & $30.8(23.5-43.8)$ & $30.4(23.5-43.8)$ & $31.7(26.8-38.9)$ \\
\hline SDS BMI & $3.7(2.1-9.2)$ & $3.6(2.1-9.2)$ & $4.0(2.3-6.8)$ \\
\hline WC $(\mathrm{cm})$ & $95.5 \pm 10.46$ & $94.4 \pm 10.92$ & $100.0 \pm 6.99^{*}$ \\
\hline $\mathrm{HC}(\mathrm{cm})$ & $108.1 \pm 11.11$ & $107.0 \pm 11.6$ & $112.1 \pm 7.98^{*}$ \\
\hline WHR & $0.88 \pm 0.06$ & $0.88 \pm 0.06$ & $0.89 \pm 0.04$ \\
\hline WHtR & $0.58 \pm 0.05$ & $0.58 \pm 0.05$ & $0.59 \pm 0.04$ \\
\hline$\%$ FAT & $34.8(20.2-53.1)$ & $34.3(25.9-53.1)$ & $36.5(20.2-49.0)$ \\
\hline $\mathrm{TC}(\mathrm{mg} / \mathrm{dl})$ & $176.2 \pm 31.59$ & $175.2 \pm 32.1$ & $179.7 \pm 30.33$ \\
\hline $\mathrm{HDL}-\mathrm{C}(\mathrm{mg} / \mathrm{dl})$ & $42.9 \pm 9.6$ & $45.4 \pm 8.89$ & $33.5 \pm 5.44^{* * *}$ \\
\hline $\mathrm{LDL}-\mathrm{C}(\mathrm{mg} / \mathrm{dl})$ & $104.8 \pm 28.43$ & $104.3 \pm 27.72$ & $106.5 \pm 31.75$ \\
\hline TG (mg/dl) & $\begin{array}{l}129.0 \\
(39.0-458.0)\end{array}$ & $\begin{array}{l}116.0 \\
(39.0-318.0)\end{array}$ & $\begin{array}{l}168.0 \\
(101.0-458.0)^{* * *}\end{array}$ \\
\hline $\mathrm{TG} / \mathrm{HDL}-\mathrm{C}$ & $3.16(0.55-14.31)$ & $2.74(0.55-12.72)$ & $5.33(2.53-14.31)^{* * *}$ \\
\hline Fasting glucose (mg/dl) & $83.0(59.0-106.0)$ & $82.0(59.0-101.0)$ & $84.0(73.0-106.0)$ \\
\hline Fasting insulin $(\mu \mathrm{lU} / \mathrm{ml})$ & $15.3(4.0-51.0)$ & $14.5(4.0-51.0)$ & $19.0(9.5-38.9) *$ \\
\hline HOMA & $3.1(0.69-11.21)$ & $2.89(0.69-11.21)$ & $3.98(1.83-9.92)$ \\
\hline QUICKI & $0.14(0.12-0.18)$ & $0.14(0.12-0.18)$ & $0.13(0.12-0.15)$ \\
\hline OGIS & $410.5 \pm 71.10$ & $417.14 \pm 70.02$ & $385.7 \pm 71.71$ \\
\hline FGIR & $5.53(1.75-17.5)$ & $5.76(1.75-17.5)$ & $4.46(2.39-8.65) *$ \\
\hline Matsuda & $3.02(0.73-11.91)$ & $3.27(0.73-11.91)$ & $2.23(1.11-4.68)^{*}$ \\
\hline $\mathrm{SBP}(\mathrm{mmHg})$ & $117.4 \pm 10.25$ & $115.5 \pm 9.75$ & $123.3 \pm 9.76^{* *}$ \\
\hline $\mathrm{DBP}(\mathrm{mmHg})$ & $72.0(55.0-100.0)$ & $73.0(55.0-90.0)$ & $71.0(67.0-100.0)$ \\
\hline
\end{tabular}

Data are presented as mean \pm standard deviation (S.D.) or median with minimum and maximum values, as appropriate. MS, Metabolic syndrome; BMI, Body Mass Index; SDS BMI, Standard deviation score of Body Mass Index; WC, Waist circumference; HC, Hip circumference; WHR, Waist to hip ratio; WHtR, Waist to height ratio; \% FAT, \% of body mass; TC, Total cholesterol; TG, Triglycerides; HOMA-IR, Homeostasis model assessment for insulin resistance index; QUICKI, Quantitative insulin sensitivity check index; OGIS, Oral glucose insulin sensitivity index; FGIR, Fasting glucose to insulin ratio; SBP, Systolic blood pressure; DBP, Diastolic blood pressure. ${ }^{* * *} p<0.001,{ }^{* *} p<0.01,{ }^{*} p<0.05$

syndrome. AUC for the TG/HDL-C ratio was the largest: $0.893,95 \% \mathrm{Cl}: 0.809-0.977$ (Table 4), indicating the superiority of the insulin resistance parameter to others for risk prediction of MS development. Moreover, for 1 unit increase in the TG/HDL-C, the odds for having the metabolic syndrome increased by 2.09 times (OR $2.09,95 \%$ CI: $1.37-3.20, p=0.001)$.

\section{DISCUSSION}

The growing number of children and adolescents with overweight and obesity is an unsettling problem on a global scale. According to the World Health Organization report, in 2014 the number of children under the age of 5 years affected by overweight or obesity reached 41 million. Prevalence of obesity is much higher in the developed countries (WHO, 2016). When compared to other European countries, the incidence of obesity and overweight in Poland is at an average level.

With higher fat mass accumulation, a higher frequency of atherogenic lipid profile, diabetes mellitus, metabolic syndrome and arterial blood pressure is found. Excessive weight gain in childhood increases the chance of becom-

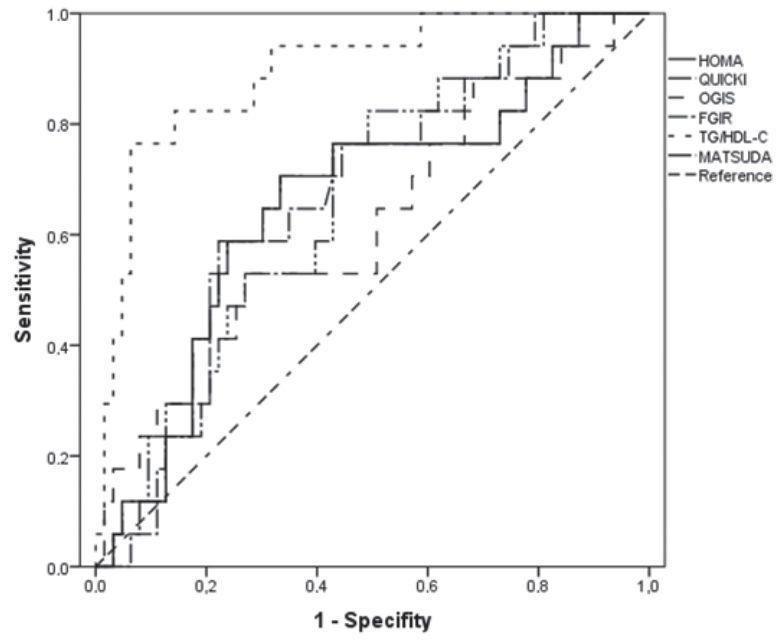

Figure 2. Receiver operating characteristic (ROC) curves for TG/ HDL-C and other surrogate insulin resistance indices in prediction of the metabolic syndrome. 
Table 3. Comparison of anthropometric and biochemical parameters, surrogate insulin resistance measurements and blood pressure in group of obese children divided according to the TG/HDL-C value

\begin{tabular}{|c|c|c|c|}
\hline \multirow{2}{*}{ Variable } & \multicolumn{3}{|l|}{ Obese children } \\
\hline & Total $(n=122)$ & $\mathrm{TG} / \mathrm{HDL}-\mathrm{C}<3 \quad(\mathrm{n}=64)$ & $\mathrm{TG} / \mathrm{HDL}-\mathrm{C} \geq 3 \quad(\mathrm{n}=58)$ \\
\hline Height $(\mathrm{cm})$ & $156.0(110.0-187.1)$ & $155.1(120.0-177.2)$ & $156.0(110.0-187.1)$ \\
\hline Body weight $(\mathrm{kg})$ & $72.34 \pm 24.11$ & $68.78 \pm 24.04$ & $74.25 \pm 22.95$ \\
\hline $\mathrm{BMI}\left(\mathrm{kg} / \mathrm{m}^{2}\right)$ & $28.8(20.7-43.8)$ & $27.55(20.7-43.6)$ & $29.2(23.4-42.7)$ \\
\hline SDS BMI & $2.7(2.0-4.8)$ & $2.73(2.0-4.77)$ & $2.7(2.18-3.96)$ \\
\hline$W C(\mathrm{~cm})$ & $90.27 \pm 12.27$ & $87.79 \pm 12.54$ & $92.02 \pm 11.20$ \\
\hline $\mathrm{HC}(\mathrm{cm})$ & $101.43 \pm 14.01$ & $100.21 \pm 14.48$ & $101.74 \pm 13.17$ \\
\hline WHR & $0.89 \pm 0.05$ & $0.88 \pm 0.06$ & $0.91 \pm 0.05^{* *}$ \\
\hline WHtR & $0.58 \pm 0.05$ & $0.58 \pm 0.05$ & $0.59 \pm 0.04$ \\
\hline$\%$ FAT & $33.5(20.2-53.1)$ & $32.75(25.9-46.3)$ & $34.8(20.2-49.0)$ \\
\hline Fasting glucose $(\mathrm{mg} / \mathrm{dl})$ & $83.6 \pm 10.3$ & $83.58 \pm 11.36$ & $83.81 \pm 9.3$ \\
\hline Fasting insulin (ulU/ml) & $14.0(4.0-51.0)$ & $12.3(4.0-51.0)$ & $15.4(6.5-48.0)^{* *}$ \\
\hline $\mathrm{TC}(\mathrm{mg} / \mathrm{dl})$ & $176.9 \pm 30.03$ & $172.9 \pm 28.44$ & $181.55 \pm 31.23$ \\
\hline $\mathrm{HDL}-\mathrm{C}(\mathrm{mg} / \mathrm{dl})$ & $42.0(25.0-92.0)$ & $50.5(37.0-92.0)$ & $36.0(25.0-56.0)^{* * *}$ \\
\hline $\mathrm{LDL}-\mathrm{C}(\mathrm{mg} / \mathrm{dl})$ & $105.8 \pm 27.2$ & $103.0 \pm 25.8$ & $109.16 \pm 28.5$ \\
\hline $\mathrm{TG}(\mathrm{mg} / \mathrm{dl})$ & $123.0(39.0-458.0)$ & $100.5(39.0-150.0)$ & $162.0(103.0-458.0)^{* * *}$ \\
\hline HOMA-IR & $2.89(0.69-11.21)$ & $2.63(0.69-11.21)$ & $3.22(1.17-10.55)^{*}$ \\
\hline QIUCKI & $0.14(0.12-0.18)$ & $0.14(0.12-0.18)$ & $0.14(0.12-0.16)^{* * *}$ \\
\hline OGIS & $\begin{array}{l}425.65 \\
(250.34-725.96)\end{array}$ & $\begin{array}{l}432.63 \\
(250.34-643.94)\end{array}$ & $\begin{array}{l}417.94 \\
(289.6-725.96)\end{array}$ \\
\hline Matsuda & $3.29(0.73-17.86)$ & $3.58(0.73-17.86)$ & $3.0(1.04-9.44)^{*}$ \\
\hline FGIR & $5.8(1.7-18.8)$ & $6.21(1.75-18.84)$ & $5.23(1.85-13.69)^{* *}$ \\
\hline $\mathrm{SBP}(\mathrm{mmHg})$ & $113.5(96.0-140.0)$ & $110.0(100.0-140.0)$ & $118.5(96.0-134.0)$ \\
\hline $\mathrm{DBP}(\mathrm{mmHg})$ & $70.0(55.0-100.0)$ & $60.0(60.0-100.0)$ & $70.0(55.0-96.0)$ \\
\hline
\end{tabular}

Data are presented as mean \pm standard deviation (S.D.) or median with minimum and maximum values, as appropriate. BMI, Body Mass Index; SDS BMI, Standard deviation score of Body Max Index; WC, Waist circumference; HC, Hip circumference; WHR, Waist to hip ratio; WHtR, Waist to height ratio; \% FAT, \% of body mass; TC, Total cholesterol, TG, Triglycerides; HDL-C, High-density lipoprotein cholesterol; LDL-C, Low-density lipoprotein cholesterol; HOMA-IR, Homeostasis model assessment for insulin resistance index; QUICKI, Quantitative insulin sensitivity check index; OGIS, Oral glucose insulin sensitivity index; FGIR, Fasting glucose to insulin ratio; SBP, Systolic blood pressure; DBP, Diastolic blood pressure. ${ }^{* * *} p<0.001$, ${ }^{* *} p<$ $0.01,{ }^{*} p<0.05$

ing obese in adulthood and can lead to cardiovascular diseases (Litwin, 2014). Kasley and coworkers (Kasley et al., 2014) have demonstrated that the health consequences of childhood obesity may be present even after weight loss.

A key role in the induction of the above-mentioned changes is played by visceral fat mass and insulin resistance (IR). Central obesity is the most unfavourable because adipocytes are more hormonally and metabolically active, and regulate numerous signal pathways. Insulin resistance disturbs glucose homeostasis, which is associated with reducing the sensitivity of the target tissues to insulin, despite its normal or increased serum levels. Moreover, IR increases the glycogenolysis process in the liver, and impacts lipoprotein metabolism which together with other components of the metabolic syndrome contribute to the development of atherosclerosis (Ten, 2004; Levy-Marchal et al., 2010). Many studies have confirmed the association of IR with ischemic heart disease and cardiovascular mortality (Laakso et al., 1991). An epidemiological study showed that more than half of obese children have impaired insulin signalling (according to the National Health and Nutrition Examination Survey, NHANES - 52.1\%, in the Polish study - 58\%) (Lee et al., 2006; Skowrońska et al., 2007). Therefore, an early detection of children with IR and their treatment can effectively delay further development of unfavourable metabolic and hemodynamic disturbances.

Methods used to diagnose insulin resistance are based on simultaneous measurements of glucose and insulin.

Table 4. Area under the curve (AUC) for the TG/HDL-C ratio and other surrogate insulin resistance indices in prediction of the metabolic syndrome.

\begin{tabular}{llll}
\hline Variable & AUC & $95 \% \mathrm{Cl}$ & $p$-value \\
\hline HOMA-IR & 0.6592 & $0.5109-0.8075$ & 0.045 \\
\hline QUICKI & 0.6592 & $0.5109-0.8075$ & 0.045 \\
\hline OGIS & 0.6209 & $0.4656-0.7762$ & 0.128 \\
\hline FGIR & 0.6681 & $0.5338-0.8024$ & 0.034 \\
\hline TG/HDL-C & 0.8936 & $0.8098-0.9773$ & 0.000 \\
\hline Matsuda & 0.6639 & $0.5305-0.7972$ & 0.039 \\
\hline
\end{tabular}

HOMA-IR- Homeostasis model assessment for insulin resistance index, QUICKI, Quantitative insulin sensitivity check index; OGIS, Oral glucose insulin sensitivity index; FGIR, Fasting glucose to insulin ratio; TG/ HDL-C, Triglycerides to high-density lipoprotein cholesterol ratio; AUC, area under the curve; $\mathrm{Cl}$, confidence interval 
The "gold standard" of IR measurement is a metabolic euglycemic clamp, but this method is laborious and expensive, so it is mainly used for scientific purposes only. The most commonly used method for the diagnosis of IR is the homeostasis model assessment for insulin resistance index (HOMA-IR). This index correlates well with the metabolic euglycemic clamp (Bonora et al., 2000) and is more reliable than other surrogate IR markers, such as FGIR and QUICKI (Keskin et al., 2005). But there is no cut-off point for estimation of IR in children. HOMA-IR values vary depending on sex, age and pubertal stage. In a few studies, different cut-off points have been demonstrated (Keskin et al., 2005; Reinehr et al., 2004; Shashaj et al., 2016).

Unexpectedly, the triglyceride to high-density lipoprotein cholesterol concentration ratio (TG/HDL-C) was found to be associated with insulin resistance. McLaughlin and co-workers (McLaughlin et al., 2003) suggested that this indicator could be an alternative tool for insulin resistance diagnosis. In that study, it was found that the TG/HDL-C ratio $\geq 3$ correlated well with the insulin resistance. A strong correlation between the TG/ HDL-C and HOMA-IR was confirmed in a cross - sectional study of the Korean population (Kang et al., 2012; Park et al., 2016) and in indigenous Argentinean children (Hirschler et al., 2013). Similar results were obtained in groups of overweight and obese children (Bridges et al., 2016; Iwani et al., 2017), in which the relationship between the TG/HDL-C ratio and the hiperinsulinemic - euglicemic clamp (Giannini et al., 2011), and other indirect measurements of insulin resistance, such as QUICKI (Olson et al., 2012) and WBISI (whole body insulin sensitivity index) (Giannini et al., 2011), were documented. Moreover, Giannini and co-workers (Giannini et al., 2011) found that this association is significant only in obese Caucasian children, but not in Hispanic or African American children, so the TG/ HDL-C ratio may be ethnically dependent. Most often, this is explained by racial differences in the lipid profile (Sumner et al., 2005). In our study, which included Polish obese children and adolescents, the TG/HDL-C ratio significantly correlated with HOMA-IR and also with other surrogate insulin resistance indices (QUICKI, FGIR, OGIS, Matsuda), as well as with fasting insulin and OGTT insulin levels.

Other studies had also highlighted that a higher TG/ HDL-C ratio is associated with an unfavourable cardiometabolic profile (Berrington et al., 2010; Olson et al, 2012; Kang et al., 2012; Iwani et al., 2017). With increasing percentiles of the TG/HDL-C ratio, apart from HOMA-IR, the values of BMI, waist circumference, fasting plasma glucose, total cholesterol level, and systolic and diastolic blood pressure were rising (Di Bonito et al., 2012; Hirschler et al, 2015; Iwani et al., 2017). Our research also provides evidence of the association between the TG/HDL-C ratio and central obesity assessed by using waist circumference, lipid profile and systolic blood pressure; however we did not find a correlation with carbohydrate glucose metabolism. Di Bonito and co-workers (Di Bonito et al., 2012) had shown that the TG/HDL-C ratio is a predictor of left ventricular hypertrophy, independently of visceral adiposity and high blood pressure, and may be useful in the risk assessment of cardiometabolic factors also in non-obese patients.

We did not obtain a clear TG/HDL-C cut-off value for the definition of insulin resistance in childhood. Di Bonito and co-workers (Di Bonito et al., 2012) had shown that in the group of obese children, the TG to HDL-C ratio $\geq 2$ increased the risk of insulin resistance by 1.5 to 10 -fold, and so did the high blood pressure and metabolic syndrome when compared to those with the TG/HDL-C $<2.0$. In another study, Giannini and co-workers (Giannini et al., 2011) suggested a 2.27 value as a cut-off point for predicting severe IR in Caucasian obese children. On the other hand, Olson and co-workers (Olson et al., 2012) found that the TG/HDL-C $\geq 3.0$ is more specific for IR and favours the occurrence of higher HOMA-IR and BMI, blood pressure, glucose level and small dense LDL particles, and lower QUICKI and HDL-C concentration in 32 children with the TG/HDL-C $\geq 2.0$ among a group of 40 children deemed insulin resistance (HOMA $>2.45)$. In our study, we adopted the TG/HDL-C cut-off point $\geq 3.0$, and these children were characterized by a higher waist to hip ratio and increased insulin resistance.

McLaughlin and co-workers (McLaughlin et al., 2005), in their study involving 258 nondiabetic, overweight adults, had shown that the TG/HDL-C ratio above 3.5 is a good indicator of the metabolic syndrome (MS). This relationship was also observed in a children population. In the Quijada study (Quijada et al., 2008), 95\% of children with MS had an elevated TG/HDL-C to 3.5 or more. As we found in our study, the median TG/ HDL-C ratio value in children under the age of 10 years who fulfilled the IDF criteria was 5.33, and in their peers who did not meet the MS criteria it was 2.74. On the other hand, there was no significant difference in HOMA-IR values and others surrogate insulin resistance indices between both groups. Dhuper and co-workers (Dhuper et al., 2007) reported an elevated prevalence of MS in children with a high TG and low HDL-C concentration. They did not find a correlation between the presence of MS and HOMA-IR. Likewise, the Liang study (Liang et al., 2015) had shown the superiority of the TG/HDL-C ratio to the HOMA - IR index in screening metabolic syndrome in children, even after consideration of such factors as gender, age and the pubertal stage. The cut-off values for predicting MS were: for the TG/HDL-C $>1.25$ (sensitivity $80 \%$, specificity $75 \%$ ), and for HOMA - IR $>4.59$ (58.7\% and $65.5 \%$, respectively). Our study confirmed that the TG/HDL ratio is a meaningful parameter in prediction of MS. The area under the ROC curve of TG/HDL-C was the largest when compared to FGIR, QUICKI, OGIS and MATSUDA indices. The odds ratio (OR) for having MS was 2.09. As a result, this parameter can be used as a screening tool for metabolic syndrome in paediatric obese patients.

There are a lot of surrogate indices used in the assessment of insulin resistance. Complex formulas and the necessity to use parallel assessment of glucose and insulin concentrations in order to calculate the IR markers are not helpful in daily clinical routine. The generally available lipid profile test allows doctors to use the TG/ HDL-C ratio in clinical practise for identification of patients with insulin resistance and unfavorable metabolic profile. As shown in our study, the TG/HDL-C ratio seems to be a good predictor of the metabolic syndrome in obese children and adolescents.

\section{CONCLUSIONS}

This study has shown that the TG/HDL-C ratio is an inexpensive marker of insulin resistance. It may help to identify children who benefit the most from early interventions. Thanks to that, the development of IR-related diseases, such as type 2 diabetes or the metabolic syndrome, may be delayed or eliminated. In addition, the above results suggest that the TG/HDL-C ratio can be used to identify children at risk of the metabolic syn- 
drome development. Obviously, more studies are needed on a larger number of patients to confirm the above relationships and determine the correct cut-off for this indicator value.

\section{Conflict of interests}

The authors declare no conflict of interests.

\section{REFERENCES}

Berrington de Gonzalez A, Hartge P, Cerhan JR, Flint AJ, Hannan L, MacInnis RJ, Moore SC, Tobias GS, Anton-Culver H, Freeman LB, Beeson WL, Clipp SL, English DR, Folsom AR, Freedman DM, Giles G, Hakansson N, Henderson KD, Hoffman-Bolton J, Hoppin JA, Koenig KL, Lee IM, Linet MS, Park Y, Pocobelli G, Schatzkin A, Sesso HD, Weiderpass E, Willcox BJ, Wolk A, Zeleniuch-Jacquotte A, Willett WC, Thun MJ (2010) Body-Mass Index and Mortality among 1,46 Million White Adults. N Eng J Med 363: 2211-2219. http://dx.doi.org/10.1056/NEJMoa1000367

Bonora E, Targher G, Alberiche M, Bonadonna RC, Saggiani F, Zenere MB, Monauni T, Muggeo M (2000) Homeostasis model assessement closely mirrors the glucose clamp technique in the assessement of insulin sensitivity: studies in subjects with various degrees of glucose tolerance and insulin sensitivity. Diabetes Care 23: $57-63$

Bridges KG, Jarrett T, Thorpe A, Baus A, Cochran J (2016) Use of the triglyceride to HDL cholesterol ratio for assessing insulin sensitivity in overweight and obese children in rural Appalachia. J Pediatr Endocrinol Metab 29: 153-156. http://dx.doi.org/10.1515/jpem-2015-0158

Chandrasekhar J, Suchitra MM, Sachan A, Bitla AR, Srinivasa Rao PVLN (2014) Indices of insulin resistance in paediatric obesity. J Clin Sci Res 3: 7-13

Cole T.J (1990) The LMS method for constructing normalized growth standard. Eur J Clin Nutr 44: 45-60

Cole TJ, Lobstein T (2000) Establish a standard definition for child overweight and obesity worldwide: international survey. BMJ 320: 1240-1243

Di Bonito P, Moio N, Scilla C, Cavuto L, Sibilio G, Sanguigno E, Forziato C, Saitta F, Iardino MR, Di Carluccio C, Capaldo B (2012) Usefulness of the high trigliceride to HDL cholesterol ratio to identify cardiometabolic risk factors and preclinical signs of organ damage in outpatient children. Diabetes Care 35: 158-1622. http://dx.doi. org $/ 10.2337 / \mathrm{dc} 11-1456$

Dhuper S, Cohen HW, Daniel J, Gumidyala P, Agarwalla V, St Victor R, Dhuper S (2007) Utility of the modified ATP III defined metabolic syndrome and severe obesity as predictor of insulin resistance in overweight children and adolescents: a cross-sectional study. Cardiovasc Diabetol 6: 4. http://dx.doi.org/ 10.1186/1475-2840-6-4

Giannini C, Santoro N, Caprio S, Kim G, Lartaud D, Shaw M, Pierpont B, Weiss R (2011) The triglyceride-to-hdl cholesterol ratio: association with insulin resistance in obese youths of different ethnic backgrounds. Diabetes Care 34: 1869-1874. http://dx.doi. org $/ 10.2337 / \mathrm{dc} 10-2234$

Hayman LL, Meininger JC, Daniels SR, McCrindle BW, Helden L, Ross J, Dennison BA, Steinberger J, Williams CL; American Heart Association Committee on Atherosclerosis, Hypertension, and Obesity in Youth of the Council on Cardiovascular Disease in the Young; American Heart Association Council on Cardiovascular Nursing; American Heart Association Council on Epidemiology and Prevention; American Heart Association Council on Nutrition, Physical Activity, and Metabolism (2007) Primary prevention of cardiovascular disease in nursing practice: focus on children and youth: a scientific statement from the American Heart Association Committee on atherosclerosis, hypertension, and obesity in youth of the council on cardiovascular disease in the young, council on cardiovascular nursing, council on epidemiology and prevention, and council on nutrition, physical activity, and metabolism. Circu lation 116: 344-357. http://dx.doi.org/10.1161/CIRCULATIONAHA.107.184595

Hirschler V, Maccallini G, Sanchez M, Gonzalez C, Molinari C (2015) Association between triglyceride to HDL-C ratio and insulin resistance in indigenous Argentinean children. Pediatr Diabetes 16: 606612. http://dx.doi.org/10.1111/pedi.12228

Iwani NA, Jalaludin MY, Zin RM, Fuziah MZ, Hong JY, Abqariyah Y, Mokhtar AH, Wan Nazaimoon WM (2017) Triglyceride to HDL-C ratio is associated with insulin resistance in overweight and obese children. Sci Rep 7: 40055. http://dx.doi.org/10.1038/srep40055

Kang HT, Yoon JH, Kim JY, Ahn SK, Linton JA, Koh SB, Kim JK (2012) The association between the ratio of triglyceride to HDL-C ratio and insulin resistance according to waist circumference in a rural Korean population. Nutr Metab Cardiovasc Dis 12: 1054-1060. http://dx.doi.org/10.1016/j.numecd.2011.01.013
Kasley MM, Zaepfel AA, Bjornstad P, Nadeau KJ (2014) Age-related consequences of childhood obesity. Gerontology 60: 222-228. http:// dx.doi.org/10.1159/000356023

Keskin M, Kurtoglu S, Kendirci M, Atabek ME, Yazici C (2005) Homeostasis model assessment is more reliable than the fasting glucose/insulin ratio and quantitative insulin sensitivity check index for assessing insulin resistance among obese children and adolescents. Pediatrics 115: 500-503. http://dx.doi.org/10.1542/peds.2004-1921

Laakso M, Sarlund H, Salonen R, Suhonen M, Pyörälä K, Salonen JT, Karhapää P (1991) Asymptomatic atherosclerosis and insulin resistance. Arterioscler Thromb 11: 1068-1076

Lee JM, Okumura MJ, Davis MM, Herman WH, Gurney JG (2006) Prevalence and determinants of insulin resistance among U.S. adolescents. Diabetes Care 29: 2427-2432. http://dx.doi.org/10.2337/ dc06-0709

Levy-Marchal C, Arslanian S, Cutfield W, Sinaiko A, Druet C, Marcovecchio ML, Chiarelli F; ESPE-LWPES-ISPAD-APPES-APEGSLEP-JSPE; Insulin resistance in Children Consensus Conference Group (2010) Insulin resistance in children: consensus, perspective, and future directions. J Clin Endocrinol Metab 95: 5189-5198. http:// dx.doi.org/10.1210/jc.2010-1047

Liang J, Fu J, Jiang Y, Dong G, Wang X, Wu W (2015) Triglyceride and high-density lipoprotein cholesterol ratio compared with homeostasis model assessment insulin resistance indexes in screening for metabolic syndrome in the Chinese obese children: a cross section study. BMC Pediatr 15: 138. http://dx.doi.org/10.1186/s12887$015-0456-y$

Litwin SE (2014) Childhood obesity and adulthood cardiovascular disease: quantifying the lifetime cumulative burden of cardiovascular risk factors. I Am Col Cardiol 64: 1588-1590. http://dx.doi. org/10.1016/j.jacc.2014.07.962

McLaughlin T, Abbasi F, Cheal K, Chu J, Lamendola C, Reaven G (2003) Use of metabolic markers to identify overweight individuals who are insulin resistant. Ann Intern Med 139: 802-809

Nadeau KJ, Maahs DM, Daniels SR, Eckel RH (2011) Childhood obesity and cardiovascular disease: links and prevention strategies. Nat Rev Cardiol 8: 513-525. http://dx.doi.org/ 10.1038/nrcardio.2011.86

Olson K, Hendricks B, Murdock DK (2012) The triglyceride to HDL ratio and its relationship to insulin resistance in pre- and postpubertal children: observation from the Wausau SCHOOL project. Cholesterol 2012: 794252. http://dx.doi.org/10.1155/2012/794252

Ostrowska-Nawarycz L, Nawarycz T (2008) Norms of arterial blood pressure in children and adolescents - experience from the city of Lodz. Arterial Hypertension 11: 138-150

Park JM, Lee JY, Dong JJ, Lee DC, Lee YJ (2016) Association between the triglyceride to high-density lipoprotein cholesterol ratio and insulin resistance in Korean adolescents: a nationwide population-based study. J Pediatr Endocrinol Metab 29: 1259-1265. http:// dx.doi.org/ 10.1515/jpem-2016-0244

Pyorala M, Miettinen H, Laakso M, Pyörälä K (1998) Hyperinsulinemia and the risk of stroke in healthy middle-aged men: The 22year follow-up results of the Helsinki Policemen Study. Stroke 29: 1860-1866

Quijada Z, Paoli M, Zerpa Y, Camacho N, Cichetti R, Villarroel V, Arata-Bellabarba G, Lanes R (2008) The triglyceride/HDL-cholesterol ratio as a marker of cardiovascular risk in obese children; association with traditional and emergent risk factors. Pediatric Diabetes 9: 464-471. http://dx.doi.org/10.1111/j.1399-5448.2008.00406.x

Reinehr T, Andler W (2004) Changes in the atherogenic risk factor profile according to degree of weight loss. Arch Dis Child 89: 419_ 422

Shashaj B, Luciano R, Contoli B, Morino GS, Spreghini MR, Rustico C, Sforza RW, Dallapiccola B, Manco M (2016) Reference ranges of HOMA-IR in normal-weight and obese young Caucasian. Acto Diabetologica 53: 251-260. http://dx.doi.org/10.1007/s00592-0150782-4

Skowrońska B, Fichna P (2007) Od otyłości prostej do cukrzycy typu 2 u dzieci i młodzieży. Standardy Medyczne 4: 277-281

Sumner AE, Finley KB, Genovese DJ, Criqui MH, Boston RC (2005) Fasting triglyceride and the triglyceride - HDL cholesterol ratio are not markers of insulin resistance in African Americans. Arch Intern Med 165: 1395-1400. http://dx.doi.org/10.1001/ archinte.165.12.1395

Ten S, Maclaren N (2004) Insulin resistance syndrome in children. J Clin Endocrinol Metab 89: 2526-2539. http://dx.doi.org/10.1210/ jc. $2004-0276$

World Health Organization (WHO). Consideration of the evidence on childhood obesity for the Commission on Ending Childhood Obesity: report on the ad hoc working group on science and evidence on ending childhood obesity. Geneva, Switzerland 2016

Zimmet P, Alberti K, Kaufman F, Tajima N, Silink M, Arslanian S, Wong G, Bennett P, Shaw J, Caprio S, IDF Consensus Group (2007) The metabolic syndrome in children and adolescents - an IDF consensus report. Pediatr Diabetes 8: 299-306. http://dx.doi. $\operatorname{org} / 10.1111 /$ j.1399-5448.2007.00271.x 